\title{
Online, Practical, and Free Cataloging Resources
}

\section{An Annotated Webliography}

\author{
John Baga, Lona Hoover, and Robert E. Wolverton Jr.
}

This comprehensive annotated webliography describes online cataloging resources that are free to use, currently updated, and of high quality. The major aim of this webliography is to provide assistance for catalogers who are new to the profession, unfamiliar with cataloging specific formats, or unable to access costly print and subscription resources. The annotated resources include general websites and webpages, databases, workshop presentations, streaming media, and local documentation. The scope of the webliography is limited to resources reflecting traditional cataloging practices using the Anglo-American Cataloguing Rules, 2nd edition, RDA: Resource Description and Access, and MAchine Readable Cataloging (MARC) standards. Non-MARC metadata schemas like Dublin Core are not covered. Most components of cataloging are represented in this webliography, such as authority control, classification, subject headings, and genre terms. Guidance also is provided for cataloging miscellaneous formats including sound and videorecordings, streaming media, e-books, video games, graphic novels, kits, rare materials, maps, serials, realia, government documents, and music.

John Baga (jbaga@library.msstate.edu) is Assistant Professor and Monographic Cataloger, Lona Hoover (Ihoover@ library.msstate.edu) is Associate Professor and Monographic Cataloger, and Robert E. Wolverton Jr. (bwolverton@ library.msstate.edu) is Associate Professor and Database Maintenance/ Authority Control Librarian, Mississippi State University Libraries, Mississippi State. Submitted August 7, 2012; tentatively accepted September 8, 2012, pending modest revisions; revision submitted September 25, 2012, and accepted for publication.
C atalogers today face numerous challenges in their work-ever-changing formats of items to catalog; keeping up with new cataloging rules and standards; lack of additional catalogers to help with training and workflow; and minimal budgets to purchase cataloging-related resources. In addition, today's librarians with a library and information science degree may not have taken cataloging courses as part of their curricula, leading to uncertainty concerning which resources to use when facing cataloging issues.

To assist new and veteran catalogers in identifying and evaluating a variety of cataloging resources available online, the authors have developed an annotated webliography. The authors' intent in creating this webliography is to help beginning catalogers in the field, save catalogers time with a selection of practical one-stop resources, pinpoint free resources for libraries with limited budgets and staff, and update the literature of annotated bibliographies and webliographies for catalogers.

The scope of the webliography is limited to resources used in traditional cataloging based on the Anglo-American Cataloguing Rules 2nd edition (AACR2), RDA: Resource Description and Access, and MAchine Readable Cataloging (MARC) standards. ${ }^{1}$ Therefore, the webliography does not cover Dublin Core, 
Encoded Archival Description, and other non-MARC metadata schemas.

\section{Why a Webliography?}

Numerous annotated bibliographies related to cataloging have been written over the past several decades. Specific topics covered in these annotated bibliographies have included authority control; electronic serials and continuing resources; maps; research in cataloging and classification; and theses and dissertations. Wolverton, and Russell and Spillane address authority control. ${ }^{2}$ Blosser, Hagan, and Zhang speak to electronic serials and continuing resources. ${ }^{3}$ Resources for maps appear in bibliographies by Kandoian and Plummer. ${ }^{4}$ Conway's annotated bibliography presents research in cataloging and classification. ${ }^{5}$ Wolverton and Hoover cover theses and dissertations. ${ }^{6}$ In addition to annotated bibliographies on specific aspects of cataloging, others have provided a broader view of cataloging resources. ${ }^{7}$

While several annotated bibliographies in the past have focused on cataloging resources in print format, advances in technology during the last two decades have helped shift the accessibility of such resources from print to web-based. This has resulted in the development and use of the term, webliographies, to describe annotated resources available via the web.

Webliographies of cataloging resources have a number of advantages over bibliographies of print resources. They may be bookmarked so that catalogers can easily access them at point of need. They provide information that is more likely to be current and continuously updated than print resources. Lastly, webliographies point the way to information that may cost less to access than the print equivalent. $^{8}$

A key goal of this webliography is to help catalogers new to the profession find reliable resources to aid their work. Most library science graduates are not fully equipped with the knowledge and skills needed to step into a full-time cataloging position. ${ }^{9}$ Much of their training must then be acquired in the workplace. ${ }^{10}$ Therefore the authors designed the webliography to include vital resources that beginning catalogers should know and use. As a corollary, the webliography should help novice catalogers identify the major authorities, organizations, and individual experts within the cataloging community.

In addition to helping new catalogers, the webliography is intended to benefit those seeking help with areas of cataloging in which they may not be experts, such as authority control, genre terms, and cataloging specific formats. Catalogers must tackle a diversity of formats, keep up with best practices, and apply a variety of rules and standards: this webliography outlines crucial resources to handle most formats and cataloging issues.

Another aim of this webliography is saving the cataloger time and energy. The web has thousands of cataloging-related resources; a Google search using the search phrase in quotes, "cataloging resources," results in more than 11,000 hits. This webliography provides relevant, vetted, and categorized online resources for most cataloging situations.

According to the 2012 special issue of American Libraries, the current economic recession has struck libraries hard and resulted in a widespread trend of "stagnating budgets" for all library types. ${ }^{11}$ Consequently, many libraries have experienced reductions in library staff or lack of funds to purchase print or subscription cataloging resources. Taking the current budget cuts into account, this webliography presents only freely available resources on the web. Online subscription-based resources like Cataloger's Desktop and Classification Web, training courses, and commercial webinars are not included. ${ }^{12}$

Some libraries, regardless of budget constraints, employ a small cataloging staff or a single cataloger, especially in the case of school libraries and special libraries. These catalogers, burdened with the responsibility of organizing a collection by themselves, may have difficulty getting the training and help they need. The authors hope that this webliography can fill in the training gaps for solo catalogers who may not have the assistance of colleagues.

This webliography is not the first of its kind to assess resources for cataloging a broad range of formats. ${ }^{13}$ However, another webliography similar in scope has not appeared in the literature for several years. El-Sherbini included categories such as cataloging tools by types and formats of materials, authority and subject heading work, dictionaries and encyclopedias, electronic discussion groups and workshops, vendors, professional organizations, and journals and newsletters. ${ }^{14}$ Condron chose a sampling of online resources of interest to catalogers with information on such topics as departmental policies, vendor products, bibliographic standards, and training. ${ }^{15}$ Owing to the transient nature of the web, websites can disappear, URLs are prone to change, and new cataloging resources emerge every year to reflect shifts in current practice. As such, many of the previously published webliographies contain outdated websites or broken links. The present webliography is intended to showcase current, well-established, and frequently updated resources.

\section{What about RDA?}

The resources in this webliography focus largely on the current standard practice, AACR2, with additional coverage of the new cataloging standard, RDA: Resource Description and Access. By all indications RDA is a reality: it is being 
implemented by LC and other national libraries in $2013 .{ }^{16}$ However, since RDA is relatively new, and LC and Program for Cooperative Cataloging (PCC) policies are still in flux, the resources available are not as numerous or definitive as those based on AACR2. Therefore the authors have selected some key resources presently available, with the caveat that once $R D A$ is officially implemented, a surge of additional resources is likely to follow in the coming years. With the migration to RDA underway, a webliography of cataloging resources based primarily on AACR2 may seem unnecessary. However, the transition to RDA could be a slow one. Millions of legacy records in AACR2 will remain, resulting in an environment of mixed standards. Some libraries may choose not to adopt RDA and stick with AACR2 for their local purposes. Cataloging courses will likely teach AACR2 and $R D A$ side-by-side. All of these trends suggest that AACR2 is not going away, so the resources in this webliography should be relevant in the foreseeable future. Indeed, most of the resources are so well-established that they will probably be updated to integrate $R D A$. Additionally, many resources will continue to be valid despite $R D A$ : the principles of classification and subject headings may be largely unaffected by it. Even looming changes to MARC coding may not be that dramatic and the information in these resources should not become totally obsolete.

\section{Method}

The method for assembling this webliography is based on extensive web searching and comparisons of resources cited by the major cataloging websites. The authors used the Google search engine, employing search terms that included, but were not limited to, "cataloging," "cataloging resources," "cataloging tools," and "cataloging [format]." No more than twenty pages for each search result were examined. By comparing links, citations, and resource lists found on prominent cataloging websites, the authors attempted to select the most promising cataloging tools on the web. Upon collecting an extensive group of candidate websites, the authors compared and contrasted the pros and cons of each resource, using this approach to narrow down the list to a manageable size.

This webliography was designed to be a practical and instructional tool for cataloging practitioners, focusing on what the authors viewed as the best online resources representing a variety of cataloging-related topics. These annotated web resources were selected based on the following criteria:

- Quality of information-Resources were evaluated for their quality of information on each topic, the number of times they were cited by other authoritative sources, and their adherence to high standards of cataloging.
- Freely available on the web-Since the price of professional materials impedes access for many libraries with budget constraints, the webliography focuses on resources that were available at no cost.

- Comprehensiveness-Cataloging aids were selected and examined for their completeness and breadth of information.

- Currency of information-Resources not updated since 2008 were generally excluded from the webliography. However, exceptions were made in cases where the authors determined that information before that year is still usable in cataloging practices.

- Regularly maintained and updated -Given the everchanging information available via the web, preference was given to sites that were regularly maintained and updated with a minimal amount of broken links.

- Authoritative individuals and organizationsResources created and maintained by reputable individuals or groups who appeared knowledgeable about the cataloging topics being addressed were favorably selected.

- Ease of access-Because time is valuable to catalogers, websites were selected that could be accessed quickly with a minimal number of clicks to get to the desired information. Ease of navigation within the site also was assessed.

- Utility-Resources intended to aid catalogers in doing their work, whether through practical examples or a quick-reference display of information, were especially favored.

- Readability-Preference was given to websites that presented information in an easy-to-read format with agreeable color contrasts, fonts, text layout, aesthetic design, and clear organization.

The resources in the webliography are arranged alphabetically under the following areas of cataloging:

- General Cataloging Resources

- Authority Control

- Classification and Cuttering

- Subject Headings, Form/Genre Terms, and Controlled Vocabularies

- Cataloging Tools by Format and Type

○ Art Books, Belles Lettres, Foreign Language, and Biblical Materials

- Audiovisual Materials

- Electronic Resources

- Electronic Books

- Streaming Media

- Video Games

○ Government Documents

$\circ$ Graphic Novels 


\author{
$\circ$ Kits \\ - Maps \\ - Music Scores and Sound Recordings \\ - Realia \\ - Reproductions \\ - Serials \\ - Special Collections, Rare Books, Manuscripts, and \\ Archival Materials \\ - Theses and Dissertations, Technical Reports, and \\ Offprints \\ - Miscellaneous Cataloging Resources \\ - $R D A$
}

\section{General Cataloging Resources}

AUTOCAT. Accessed September 9, 2012. https://istserv.syr .edu/scripts/wa.exe?A0=AUTOCAT.

AUTOCAT has been a staple for catalogers since 1991. This electronic mailing list facilitates inquiries and information sharing on cataloging issues. Thousands of questions have been asked and answered ranging from basic MARC field help to problems with complicated formats. Contributing to AUTOCAT and searching the archives requires a subscription, but this is free and simple to do. The archives are updated in real time and enable basic keyword or advanced search strings. Since AUTOCAT has documented cataloging questions for more than twenty years, the archives provide a wealth of information shared by real world catalogers. Indeed, searching the archives is a surefire method of finding information that no other resource can offer.

LeGrow, Lynne, comp. "Library Cataloguing Aids.” Accessed September 9, 2012. www3.ns.sympatico.ca/allegrow/cat.htm.

This site is a hub of cataloging resources organized by categories for AACR2, authority work, cataloging by format, Library of Congress Subject Headings (LCSH), and MARC, among others. Interspersed throughout the list of resources are humorous visuals and tidbits of information that will appeal to catalogers. Other features include direct links to past issues of the LC Cataloging Service Bulletin, active cataloging blogs, electronic discussion lists, and even a section for recent LCSH changes or additions. Although Library Cataloguing Aids is maintained by Lynne LeGrow, a cataloger at Halifax Public Libraries in Nova Scotia, Canada, the site is not geared exclusively toward Canadian catalogers; most of the resources are of broad relevance. While the site has a single-page layout, in addition to several broken links, it brings together many practical online resources for catalogers.

Library Corporation. "Cataloger's Reference Shelf." Accessed September 9, 2012. www.itsmarc.com/crs/crs.htm.
Catalogers Reference Shelf (CRS) is a free online collection of resources maintained by The Library Corporation (TLC) that delivers quick, easily accessed information about cataloging standards. Navigating CRS is facilitated in three ways: colorful buttons, a table of contents below the labeled buttons, and a menu on the sidebar. Content is based on the LC's MARC manuals and other reference works available through the LC Cataloging Distribution Service. Thus the information on MARC codes is essentially the same as what appears on the LC MARC Standards website. On CRS, however, the information is presented with hyperlinks so that less manual scrolling is required. The remaining resources are based on manuals available through the LC Cataloging Distribution Service with copyright dates ranging from 1984 through 2007. The site offers tools for cataloging specific types of materials, such as archival moving image materials, serials, graphic materials, loose leaf publications, map cataloging, and rare materials, as well as general resources that apply to cataloging in general: classification, Cutter tables, Library of Congress Rule Interpretations, application of LCSH, the Subject Cataloging Manual: Classification and Subject Cataloging Manual: Shelflisting, and the NACO Participants' Manual. ${ }^{17}$

Library of Congress. "BIBCO-Monographic Bibliographic Record Program of the PCC." Accessed September 9, 2012. www.loc.gov/aba/pcc/bibco/index.html.

BIBCO is the bibliographic record component of the Program for Cooperative Cataloging (PCC) and allows PCC Name Authority Cooperative Program (NACO) members to contribute high quality monographic records in all formats to national databases. The BIBCO website provides an overview of the program, FAQs on how to join, cataloging resources, summary reports of BIBCO meetings, annual reports, and lists of participating libraries, trainers, and training materials.

The website also contains a link to the BIBCO Participants' Manual, edited by Carol Hixson, David Banush, and Ana Cristán, which gives an overview of the program, including its history, criteria for membership, training, and creation of BIBCO records. Policies and practices of the program are described in detail, including bibliographic record content, authority control, and genre/form terms. In addition, LC, Dewey, National Library of Medicine, and Superintendent of Documents (SuDocs) classifications are discussed, along with record maintenance, retrospective conversion, and tools for BIBCO participants. The final section of the manual contains a variety of BIBCO sample bibliographic records, including core and full-level records. While not all libraries are BIBCO members, the information on this website can be helpful to new catalogers because it supplies guidelines for the development of high-quality bibliographic records. 
Library of Congress, Cataloging Distribution Service. Cataloging Service Bulletin. Accessed September 9, 2012. www .loc.gov/cds/PDFdownloads/csb.

The Cataloging Service Bulletin (CSB) provided new and revised information about LC cataloging and classification practices and policies before its cessation in 2010. These included AACR2, Library of Congress Rule Interpretations (LCRI), new LC Subject Headings of Current Interest, Revised LC Subject Headings, Subject Headings Replaced by Name Headings, and American Library Association/ Library of Congress Romanization tables. In addition, the CSB provided news on cataloging publications and cataloging projects. While the CSB ceased publication in 2010, PDFs of issues from Summer 1978 to Fall 2010 are archived on the website; much of the information in these issues is still relevant and may be helpful to catalogers.

Library of Congress, Network Development and MARC Standards Office. "MARC Standards." Accessed September 9, 2012. www.loc.gov/marc.

MARC Standards is the authoritative source for the standards of communicating bibliographic information in machine-readable form. Topics include bibliographic data, authority control, holdings data, classification data, and community information. There are code lists for geographic areas, languages, relators, and other lists of controlled vocabularies, such as genre terms and $R D A$ carrier, content, and media types. MARC developments, updates, and general information are, likewise, easily accessed. Despite the large quantity of resources that can be found here, the site is wellorganized and intuitive to navigate.

Library of Congress. "Program for Cooperative Cataloging." Accessed September 9, 2012. www.loc.gov/aba/pcc.

The Program for Cooperative Cataloging (PCC) website provides guidelines for the creation of high-quality bibliographic and authority records that can be shared by libraries and users worldwide, based on mutually accepted standards. To accomplish this goal, the PCC developed four component programs that focus on specific cataloging-related objectives: Monographic Bibliographic Record Program (BIBCO), Cooperative Online Serials Program (CONSER), Name Authority Cooperative Program (NACO), and Subject Authority Cooperative Program (SACO). The PCC site functions as a hub of resources. While not all libraries belong to a PCC program, the PCC website and its component websites provide a wealth of resources that can be helpful to new or veteran catalogers. The PCC website contains links to membership benefits, activities and reports, and task group information. It also provides a link to the Catalogers Learning Workshop site, which contains freely available information on resources related to the organization and classification of information, including workshop course materials and webcasts. Recent additions to the site include resources related to RDA and Functional Requirements for Bibliographic Records (FRBR). ${ }^{18}$

OCLC. OCLC Bibliographic Formats and Standards, 4th ed. Accessed September 9, 2012. www.oclc.org/bibformats/ en.

OCLC's Bibliographic Formats and Standards (BFAS) is probably one of the most frequently used resources for the everyday cataloger using OCLC Connexion or for catalogers seeking information that is clearly and concisely presented. When faced with uncertainties about MARC tags, subfields, and indicators, BFAS is the most convenient and authoritative source to consult. It delivers in-depth information on MARC fields used in OCLC WorldCat cataloging records, along with input standards and guidelines on entering data. In addition to describing fixed and variable MARC fields, BFAS discusses types and levels of cataloging, entry of ISBD punctuation, use of General Material Designation (GMD), and transcription of pre-AACR2 and AACR2 copy. BFAS also describes differences between full, core, minimal, and abbreviated-level cataloging and special cataloging guidelines for specific materials including theses and dissertations, reproductions and original microfilm publications, locally made videorecordings, electronic resources, and integrating resources. Guidance also is given on when to input a new record and the importance of quality assurance in OCLC records. For new catalogers, OCLC's BFAS is an invaluable tool for learning how to use MARC fields and understanding the importance of contributing high quality, shared records to WorldCat.

Pennell, Charley, and Lorraine Jackson. "Cataloguer's Toolbox." Memorial University Libraries, Memorial University of Newfoundland. Last modified August 16, 2012. Accessed September 9, 2012. http://staff.library.mun.ca/staff/ toolbox.

This impressive collection of cataloging resources is organized into eleven broad categories. The quick reference category contains three subtopics of resources organized by activity, format, and subject. Resources falling under these subtopics encompass authority work, classification, Cuttering, and subject analysis. Also included are aids for cataloging government documents, music, rare materials, remote electronic resources, serials, theses and dissertations, and audiovisual materials. There is assistance for cataloging the subjects of art, law, and medicine. Other sections of the site include MARC coding information, LC cataloging tools, electronic lists, blogs and wikis, as well as a host of additional helpful information to catalogers. Resources run the gamut from general websites, national library catalogs, and practical manuals to miscellaneous reference sites on topics such as geography and architecture. 
Special Libraries Cataloguing. "Cataloguing Cheat Sheets." Accessed September 9, 2012. http://special-cataloguing.com/ cheats.

This extensive list of cheat sheets explores nearly every facet of cataloging, from subject headings and classification to format-specific tutorials. Although intended as training documentation for Special Libraries Cataloguing staff, headed by J. McRee Elrod, the information represents standard LC/ OCLC practice and is therefore valid for most catalogers. A detailed cheat sheet has been written for nearly every format, making this site a reliable source for the jack-of-all-trades cataloger. The cheat sheets are heavily illustrated with MARC examples and are organized by area of description. Although each cheat sheet is brimming with substantial content, the layout does not always favor readability. Nevertheless, Elrod's information is dependable, current, and frequently updated.

\section{Authority Control}

FamilySearch. "Discover Your Family History." Church of Jesus Christ of Latter-day Saints. Accessed September 9, 2012. www.familysearch.org.

Established by one of the largest genealogy organizations in the world, the FamilySearch website can be used at no cost to obtain information on billions of names from numerous databases including the US Social Security Death Index, Family Tree, and International Census Records. A basic name search on the website results in a listing of people with that name, along with the index used to provide the information. Specific information on an individual depends on the particular index used, but can include a person's full name, gender, date and place of birth, date of death, names of parents, and the person's relationship to the head of the household. This site can be of great assistance to catalogers in establishing name authority records and verifying name information in bibliographic records.

Library of Congress, Cooperative Cataloging Team. NACO Participants' Manual, 3rd ed. Washington, DC: Library of Congress, 2005. Accessed September 9, 2012. www.loc.gov/ aba/pcc/naco/documents/npm3rd.pdf.

This manual was developed as a resource for training in the Name Authority Cooperative Program (NACO), which is a component of the Program for Cooperative Cataloging (PCC). The NACO Participants' Manual provides in-depth information on how to create new authority records for personal, corporate, and conference names, as well as uniform titles and geographic name headings for jurisdictions. It also covers procedures for making additions and changes to existing name authority records. The manual provides helpful detailed examination of the MARC fields used in the process of creating and revising names, and numerous examples are supplied throughout the manual to illustrate the key components of name authority records. Appendixes in the manual include information on how to join the NACO program.

OCLC. "VIAF: Virtual International Authority File." Accessed September 9, 2012. http://viaf.org.

Although VIAF began as a joint project with OCLC, the LC, the Deutsche Nationalbibliothek, and the Bibliothèque nationale de France, a growing number of other national libraries and agencies have contributed to VIAF in recent years. It serves as an access point to major personal and corporate name authority files, geographic names (jurisdiction places only), and uniform titles worldwide with the goal of providing free authoritative information to libraries and other agencies on a global scale. VIAF allows national and regional variations in authorized forms of names and uniform titles to coexist and supports needs for variations in preferred language, script, and spelling. The authority records are accessible through a search box prominently displayed at the top of the screen. Although currently under development, this database of shared authority data is potentially useful on an international scale. Information on the history, governance, and the application process to participate in the project is available at www.oclc.org/viaf/default.htm.

Schiff, Adam L. SACO Participant's Manual, 2nd ed. Washington, DC: Program for Cooperative Cataloging, 2007. Accessed September 9, 2012. www.loc.gov/aba/pcc/saco/ documents/SACOManual2007.pdf.

The second edition of this manual documents nearly every aspect of creating new subject headings under the Subject Authority Control Program (SACO), which is a component of the PCC. The manual offers information about the program, including when to make a subject proposal, how to conduct authority research for new subject proposals, guidelines, MARC 21 authority fields, and many examples of subject authority records. A section on preparing and submitting new classification proposals is provided with numerous examples given, including a section on Cutter numbers. The manual also discusses headings that are appropriate for use as free-floating subdivisions. Sample pages of new subject headings appearing on the LC's tentative weekly list and approved weekly list of reviewed proposals are provided, although recent changes in SACO procedures have changed the frequency of these lists from weekly to monthly.

\section{Classification and Cuttering}

Library Corporation. Subject Cataloging Manual, Shelflisting, 2nd edition: Contents. Accessed September 9, 2012. www.itsmarc.com/crs/mergedProjects/scmshelf/scmshelf/ contents.htm. 
The Subject Cataloging Manual, Shelflisting, second edition, specifically the "General" section, consists of notes and examples on constructing call numbers and Cuttering and thus assists in use of the LC classification schedules. Although the second edition of the manual has been replaced, much of the information is still relevant. ${ }^{19}$ It can serve as a useful guide on classification and Cuttering for catalogers lacking the updated print version or Cataloger's Desktop.

Library of Congress. "Library of Congress Classification Approved Lists." Accessed September 9, 2012. www.loc.gov/ aba/cataloging/classification/weeklylists.

This website lists new and revised LC classifications as determined by the LC Policy and Standards Division. New, revised, and obsolete class numbers are arranged in alphabetical order with captions showing their context within the classification. Regular review of this list can help keep catalogers up to date with new and revised LC classifications.

Library of Congress. "Library of Congress Classification Outline." Accessed September 9, 2012. www.loc.gov/catdir/ cpso/lcco.

The classification outline is an authoritative cataloging tool, useful for quickly surveying the main classes in the LC classification schedules. An outline for each of the main classes is provided and accessed from an A-to-Z list. Each outline offers a broad but incomplete overview of the schedule with main class, subclasses, and corresponding class numbers. The complete schedule is available through printed volumes or LC's subscription-based Classification Web.

OCLC. "DeweyBrowser beta v2.0." Accessed September 9, 2012. http://deweybrowser.oclc.org/ddcbrowser2.

OCLC's Dewey Browser enables access to approximately 2.5 million WorldCat records classified according to the Dewey Decimal Classification (DDC) system. The interface is based on WorldCat's public display and incorporates faceted searching by format, language, and audience. A tag cloud display of broad subject terms facilitates subject searches. Each record includes basic bibliographic information for the item along with its Dewey Decimal number and the holding libraries within a radius of the user's zip code. This is a good substitute resource for librarians using DDC who lack access to OCLC WorldCat FirstSearch.

OCLC. "Map LC (LCC) to Dewey (DDC) Classification." Accessed September 9, 2012. www.questionpoint.org/crs/ $\mathrm{html} / \mathrm{help} / \mathrm{en} / \mathrm{ask} / \mathrm{ask}$ _map_lcctoddc.html.

This website provides mapping of LC classes to Dewey numbers and vice versa. It is an OCLC project last updated in 2003. The website notes "that mappings to LCC classes, D, J and $\mathrm{K}$ are still in process. LCC Class R has been replaced ... by National Library of Medicine Classes QS-QZ and W." Although it is not current and is incomplete in several classes, it still can serve as a resource for catalogers transitioning from one of these classification systems to the other.

U.S. National Library of Medicine. NLM Classification 2012. Accessed September 9, 2012. www.nlm.nih.gov/class// index.html.

Here is the official National Library of Medicine (NLM) website of resources related to classification practices. The resources are comprised of introductory guides to using the NLM classification and its index, detailed outlines of NLM classes, a list of cancelled class numbers, and information about table G. Two search boxes on the page allow the user to search the NLM index or schedule and find NLM class numbers. The "quick tour" link below the search box plays a video tutorial about searching NLM classification. In addition, convenient links to the medical subject headings $(\mathrm{MeSH})$ browser, free online training modules, and the NLM catalog are provided. For beginners to NLM classification, this website is an essential starting point.

\section{Subject Headings, Form/Genre Terms, and Controlled Vocabularies}

Dutkiewicz, Scott M. "Library of Congress Genre/Form Terms for Library and Archival Materials LCGFT Moving Image Genre-Form Terms." Last updated July 16, 2012. Accessed September 9, 2012. www.olacinc.org/drupal/capc_ files/GenreFormHeadingsList.pdf.

This document is a continually updated list of all LC Genre/Form Terms (LCGFT) for moving image materials. All changes including new, modified, or cancelled terms are noted at the top of the document. While the list is similar to Joel Hahn's (see next entry), it focuses entirely on moving image materials and features more recently added or changed headings. For moving image materials, this compilation is one of the most accurate and authoritative resources of its kind.

Hahn, Joel. "LCSH Topical Headings Usable as Genre Headings." Last modified August 29, 2011. Accessed September 9, 2012. www.hahnlibrary.net/libraries/formgenre.html.

This resource is a list containing LCGFT, as well as LCSH usable as genre headings. Although the list appears in alphabetical order by default, it also can be sorted by category, thereby arranging all terms under an associated format like art, books, films, and music. Continually updated, the list is comprehensive and the terms are displayed with the correct MARC coding. Those headings specifically belonging to the LCGFT vocabulary appear in bold font to differentiate them from the other LCSH. While the list is comparable to 
Scott Dutkiewicz's (see entry above), it is missing a number of recently added LCGFT. However, the author provides an online form to submit additions and corrections. Overall, the broader scope of this list renders it useful to catalogers because it can help them find terms applicable to many formats; not just moving images materials.

Library of Congress. "Library of Congress Authorities." Accessed September 9, 2012. http://authorities.loc.gov.

Library of Congress Authorities provides authority heading information by name, subject, title, name/title, and keyword. Each authority record can be viewed as a labeled display or a MARC display, and red boxes indicate if the heading is an authorized heading or cross-reference. FAQs and search tips also are provided, helping users optimize their searching. Retrieved authority records can be downloaded, printed, or emailed.

Library of Congress. "Library of Congress Subject Headings (LCSH) Approved Lists.” Accessed September 9, 2012. www.loc.gov/aba/cataloging/subject/weeklylists.

New and changed LCSH that have been approved by the LC Policy and Standards Division (PSD) can be viewed at this website on a month-by-month basis. It covers the most recently approved subject headings and archives of previously approved headings from 1997 to the present.

Library of Congress. "Library of Congress Subject Headings Monthly Lists.” Accessed September 9, 2012. http://classifi cationweb.net/tentative-subjects.

This website displays, on a monthly basis, information about new or revised proposals for subject headings and genre/form terms, submitted by librarians and reviewed by the LC Policy and Standards Division (PSD). The proposed changes are not approved at the time of their being posted and are not to be used in current cataloging practices until final decisions are made by the PSD.

Sha, Vianne. "Guide to the Usage of LCSH Free-Floating Form Subdivisions." Last modified March 9, 2000. Accessed September 9, 2012. www.itcompany.com/inforetriever/ form_subdivisions_list.htm.

This resource is a nearly complete list of LCSH freefloating form subdivisions (\$v) arranged in alphabetical order. Each free-floater includes a scope note about its proper usage along with a MARC example. Although it has not been maintained since 2000, the list is still accurate for the most part. Since its last update, roughly fifteen new form subdivisions have been introduced and only a handful of subdivisions from this list have been modified or rendered obsolete. Despite its static existence, the list is relevant and has remained available online for more than ten years. This list will be beneficial to those lacking access to or seeking a concise alternative to the print edition of LCSH or the subscription-based Cataloger's Desktop version of "FreeFloating Subdivisions."

U.S. National Library of Medicine. "Medical Subject Headings." Accessed September 9, 2012. www.nlm.nih.gov/mesh/ MBrowser.html.

Similar to the NLM Classification website, this one focuses on Medical Subject Headings (MeSH). It includes numerous guides introducing $\mathrm{MeSH}$, a list of new headings for the current year, and links to the MeSH browser. The browser facilitates searching for MeSH authority files using keyword terms found in the main heading, qualifiers, or scope notes. The site offers a "navigate from tree top" option, which expands all classes in the tree structure for open-ended browsing. According to the browser search page, the authority file database is updated weekly.

\section{Cataloging Tools by Format or Type}

\section{Art Books, Belles Lettres, Foreign Language, and Biblical Materials}

Princeton University. "Princeton University Cataloging Documentation." Last modified April 2, 2010. Accessed September 9, 2012. http://library.princeton.edu/departments/tsd/ katmandu/catman.html.

Located throughout this website are Princeton University Library's guidelines for cataloging items in a variety of formats. What distinguishes this resource from other websites, however, are the specialized guides for dealing with art books, belles lettres, printouts of webpages, biblical materials, and foreign language materials in Greek, Hebrew, Persian, and Slavic. The guides are accessed from the documentation page and under various dropdown sections of the sidebar menu, particularly "Cataloging" and "Team/Special." Although these guides are tinged with Princeton's local policies and practices, the information is unique and potentially useful to other catalogers.

\section{Audiovisual Materials}

When cataloging audiovisual materials, the best resources to consult are issued by Online Audiovisual Catalogers (OLAC). OLAC is an international organization of catalogers dedicated to teaching others about cataloging nonprint formats. OLAC's resources include conference workshop presentations by experts in the field, as well as training documents created by special task forces. At the time of compiling this webliography, many essential resources for cataloging audiovisual formats were presentations at the OLAC biennial conference in 2010. 
Freeman, Robert. "The Return of Cataloging Unusual Sound Recordings." Slideshow presentation, OLAC Conference, Macon, Georgia, October 2010. Accessed September 9, 2012. www.olacinc.org/drupal/conference/2010/files/ OLAC\%202010-Advanced\%20Sound\%20Recordings.ppt.

Freeman's presentation provides a focused look at problematic sound recordings, such as enhanced, hybrid, encrypted, custom, and shaped CDs. DVD-Audio/SACDs, playaways, slotmusic, and remote sound files also are covered. The slides are replete with examples of MARC records and incorporate color photographs of the disc and container associated with each MARC example. While some slides cannot be understood without hearing the speaker, most convey useful information, such as fixed and variable fields unique to each format. The presentation provides a slideby-slide comparison of an AACR2 and RDA record, but this may not reflect current $R D A$ practice. In addition, several slides are presented like cheat sheets with full MARC 006/007 coding for sound and videorecordings, chief sources of information, common physical description terms (e.g., "1 sound disc"), and order of MARC 5XX notes. A bibliography of resources related to the topic is included at the end. This resource will be an asset to any cataloger of special sound recording types.

Lisius, Peter. "Basic Videorecordings." Slideshow presentation at OLAC Conference, Macon, Georgia, October 2010. Accessed September 9, 2012. www.olacinc.org/drupal/ conference/2010/files/Basic_Videorecordings_Presentation _OLAC_2010.pdf.

Lisius' workshop slides examine the process of cataloging videorecordings. They are arranged in order of MARC field beginning with the fixed fields. Topics include sources of information, when to input a new record, access points, coding the 007 , and various $5 \mathrm{XX}$ notes special to videorecordings. This workshop presentation was conducted before genre term coding was revised; therefore, the MARC examples of LCGFT are obsolete. Although the resource is essentially a collection of slides, it is instructive and sufficiently clear enough to follow without hearing the presenter. An abundance of MARC coding examples and six full MARC record examples imbue this resource with practical value to the inexperienced cataloger.

OLAC Cataloging Policy Committee, DVD Cataloging Guide Update Task Force. Guide to Cataloging DVD and Blu-ray Discs Using AACR2 and MARC 21:2008 Update (includes Correction 4/23/10 for MARBI Tag 007 Code Change). Accessed September 9, 2012. www.olacinc.org/ drupal/capc_files/DVD_guide_final.pdf.

This 71-page document offers guidelines for the descriptive cataloging of nearly all manner of DVD and Blu-ray disc types, including DVD-Video, DualDiscs, DVD-Audio, and
DVD-ROMs. Based upon work done by the 2002 OLAC DVD Cataloging Task Force, this resource was created by OLAC's DVD Cataloging Guide Update Task Force in 2008 and corrected in 2010. The guide emphasizes the descriptive cataloging process and MARC coding; subject headings and added entries are not covered. Information is presented in logical order by MARC fields with plentiful examples and clear instructions. Images of DVD disc labels, containers, and symbols for identifying a DVD's technical specifications are embedded throughout the document, which help illuminate the differences between disc types. In addition, the document provides full MARC records for each DVD/ Blu-ray disc type as well as citations for appropriate AACR2 rules, Library of Congress Rule Interpretations, and links to other resources. This manual will supply catalogers with well-organized, inclusive, and practical information needed to complete descriptive cataloging of most DVD and Blu-ray disc types.

Weitz, Jay. "Advanced Videorecordings.” Slideshow presentation, OLAC Conference, Macon, Georgia, October 2010. Accessed September 9, 2012. www.olacinc.org/drupal/con ference/2010/files/weitzVideoAdvanced.pptx.

Weitz's presentation slides will appeal to any cataloger of videorecordings. They are organized by MARC field and convey guidelines for describing video and sound characteristics, region, color broadcast system, closed captioning, and aspect ratio, among other things. The slides are laced with vivid illustrations, MARC record examples, and rule citations. They offer detailed instructions and clarification on a variety of special considerations of video cataloging. Weitz provides clear instructions for creating the MARC 245 field, pinpointing correct identifying numbers for the 024 and 028 fields, and cataloging streaming media, series dependent titles, and locally produced videos. In addition, the history of video formats is elucidated, so the cataloger will know when to trust that the date on the item is accurate. These slides are a fine complement to Peter Lisius' "Basic Videorecordings" workshop (see entry above).

Weitz, Jay. "Cataloging Digital Formats." Slideshow presentation, OLAC Conference, Macon, Georgia, October 2010. Accessed September 9, 2012. www.olacinc.org/drupal/con ference/2010/files/weitz\%20CatalogingDigitalMedia2010 .PPT.

These presentation slides by Weitz are similar in style and organization to his "Advanced Videorecordings" workshop (see entry above). Much of the content on DVDs is repeated here, but this one also encompasses Blu-ray discs, DVD-audio, playaways, dual discs, and streaming media. A history of each format is summarized to help the cataloger know that a playaway, for example, will not have a date before 2005. Most of the presentation slides are devoted to 
MARC record examples and descriptive cataloging guidelines. Information is presented succinctly with appropriate illustrations, MARC record examples, and applicable models to follow. Because of the nebulous cataloging standards associated with these digital formats, this resource will aid any cataloger dealing with a variety of video discs and streaming media.

Wynne, Susan. "Cataloging Oral History Interviews." Slideshow presentation, OLAC Conference, Macon, Georgia, October 16, 2010. Accessed September 9, 2012. www .olacinc.org/drupal/conference/2010/files/OLAC\%20 2010\%20presentation.pptx.

Wynne's workshop offers a definition of oral history, explains its importance, compares cataloging methods applicable to oral history interviews, and includes a complete descriptive cataloging walkthrough. A third of the slides are devoted to the philosophy behind oral histories and the presenter's local library practice. The remaining slides are organized by area of description and order of MARC field. The slides include sections on fixed fields, subject access (including genre headings), and authority control. Of special note is the information about constructing notes and handling unusual 5XX fields. Additionally, the workshop clarifies collection and item-level description and presents an overview of classification choices such as classing an item under biography, local history, and subject of the oral interview. A full MARC record example is provided for easy reference. Catalogers may not encounter oral histories frequently, but if and when they do, this unique resource is guaranteed to supply answers to their cataloging conundrums.

\section{Electronic Resources}

Library of Congress, Network Development and MARC Standards Office. Guidelines for Coding Electronic Resources in Leader/06. Last modified December 2007. Accessed September 9, 2012. www.loc.gov/marc/ldr06guide.html.

This LC site provides detailed information and guidelines on coding the MARC leader/06, 006, 007, and 008 for electronic resources. These coding guidelines are organized by type of e-resource with snippets of MARC records for illustration. Brief definitions for the terms represented by the codes discussed in this resource are listed in the appendixes. Although some familiarity with MARC coding and cataloging electronic resources would benefit the user of this site, a beginner could profit from using it in conjunction with additional resources.

Weitz, Jay. "Cataloging Electronic Resources: OCLC-MARC Coding Guidelines." Last modified July 11, 2006. Accessed
September 9, 2012. www.oclc.org/support/documentation/ worldcat/cataloging/electronicresources/default.htm.

This integral piece of OCLC documentation gives an overview of considerations involved in cataloging electronic resources, such as the separate record versus single record approach and treatment of integrating resources. In addition, brief sections provide guidance in applying correct MARC fixed field codes, formatting the 856 field (Electronic Location and Access) in MARC records, and handling electronic reproductions of print materials. Links to CONSER and LC cataloging manuals are included at the outset; however, the currency of these manuals ranges widely from 1997 to 2011. The site was last revised in 2006 and therefore does not account for recent changes to electronic resource cataloging. It remains vital, however, for its preliminary information, guidance for the fixed fields, and substantive section on integrating resources, all of which are still current.

\section{Electronic Books}

Yale University Library. Metadata Services. "Cataloging Online Books Electronic Editions." Last modified December 4, 2006. Accessed September 9, 2012. www.library.yale .edu/cataloging/mst/marc/obe.html.

This is Yale University Library's guide to cataloging e-books. The guide has introductory paragraphs explaining the distinctions between remote and direct access, monographs and integrating resources, and electronic edition and reproduction style cataloging. However, most of the guide is devoted to descriptive cataloging and organized in sequential order of MARC fields starting with fixed fields and moving through all applicable variable fields. The writeups for each field are concise, practical, and supplemented by examples. One disadvantage is that the webpage only displays on a small portion of the screen. The site offers a convenient table of contents with quick links to each MARC field. Although the guide incorporates some of Yale's local practice, it remains relevant to other libraries.

\section{Streaming Media}

OLAC Cataloging Policy Committee. Streaming Media Best Practices Task Force. Best Practices for Cataloging Streaming Media. Last modified March 2009. Accessed September 9, 2012. www.olacinc.org/drupal/capc_files/streamingmedia .pdf.

This is a complete guide to cataloging streaming audio and video formats. The information is relatively current, having been updated in 2009 with assistance from Jay Weitz. Sections clarify what streaming media is not and how to determine the chief source of information. Other sections describe how to create the MARC 006 (Fixed-Length Data Elements-Additional Material Characteristics) field 
and 007 (Physical Description Fixed Field) and apply correct fixed fields. Explanations also are given for choosing between a single and separate record approaches for streaming media. The body of the document takes the reader through each pertinent MARC field step-by-step. Visually supplementing the document are full MARC records for various streaming media formats as well as screenshots of what actual streaming media looks like on the web. Additionally, a list of frequent file extensions (e.g., flv and .wma) for identifying streaming media types is included.

Veve, Marielle. The Streaming Guide to Cataloging Remote Access Multimedia: A How-To Virtual Manual for Catalogers. Knoxville: Newfound Press, University of Tennessee Libraries, 2010. Accessed September 9, 2012. www.new foundpress.utk.edu/pubs/veve.

This online publication provides an engaging guide to cataloging streaming video, streaming audio, e-books, web games, and podcasts. The resource has a separate webpage devoted to each of the formats. Information is conveyed primarily through brief Flash Player video clips that look like animated PowerPoint slides. These videos illustrate the characteristics of each media format and how to catalog it. Videos for the fixed fields and each variable field have clear instructions and screenshots of MARC record examples. Unfortunately, according to a statement by the author, the guide will not be revised over time, and will not incorporate changes to cataloging policies or consideration of emerging formats. Nevertheless, it is efficiently organized, visually attractive, and informative. When cataloging peripheral formats like web games and podcasts, this guide offers exceptional information not found in many other online resources.

\section{Video Games}

Donahue, Nanette. "Cataloging the Weird Stuff." Slideshow presentation. Accessed September 9, 2012. www.slideshare .net/nanettedonohue/cataloging-the-weird-stuff.

These presentation slides offer guidance for cataloging video games, playaways, streaming media, and realia. Not many resources can be found that examine video game cataloging in such detail. While the slides on playaways, streaming media, and realia are significant, the section on video games makes this resource unique. The slides are designed with practicality in mind, showing important MARC record examples and color illustrations of the pieces being cataloged. Most of the current gaming consoles are featured: Nintendo DS, Wii, PlayStation, PlayStation Portable (PSP), and Xbox. Especially helpful are the many examples of MARC 300 (Physical Description) and 538 (System Details Note) fields, which will be unique for each console platform. The illustrations help the beginning cataloger or someone unfamiliar with the video game format understand what information to look for on the game container itself. For example, some illustrations are images of the tiny print found on games, much like credits on DVD containers. Several slides comprise a thoughtful bibliography of print and online resources for each format covered. Considerable information is available in Slideshare's "Notes on Slide" feature, viewed near the comments area of the webpage. For the cataloger unfamiliar with cataloging video games, this resource will be of tremendous value.

\section{Government Documents}

Federal Depository Library Program. FDLP Desktop. "Cataloging \& SuDoc Classification." Accessed September 9, 2012. www.fdlp.gov/cataloging.

FDLP Desktop is one of the few authoritative online resources for cataloging government documents. It includes cataloging aids concerning Congressional serial set publications and digital reproductions, as well as Government Printing Office (GPO) policies for creating separate and brief bibliographic records. The site offers classification guidelines for digital reproductions of monographs and an outline of the SuDocs classification scheme. The most important resource here is the fourth edition of GPO's Cataloging Guidelines, a 206-page manual with extensive instructions, policies, and detailed MARC record examples.

\section{Graphic Novels}

Lewis and Clark Library System. "Cataloging Graphic Novels." Last modified November 8, 2010. Accessed September 9, 2012. www.lcls.org/wp-content/uploads/2009/05/ Cataloging-Graphic-novels.pdf.

This local documentation is packed with practical descriptive cataloging and MARC field guidelines for graphic novels. The information is presented in the style of a cheat sheet demarcated with helpful headings. Although only three pages in length, the amount of information pertaining to graphic novels is solid. Instructions are direct and clear on how to code the fixed fields, enter the statement of responsibility, interpret the edition statement, construct added entry uniform titles, and handle the main entry for translations/ adaptations among other things. Aside from a cheat sheet by Special Libraries Cataloguing (see under General Cataloging Resources), very few online resources can be found on cataloging graphic novels. What makes this particular one outstanding is its concision and reader-friendly layout.

\section{Kits}

Lewis and Clark Library System "Cataloging Kits." Last modified March 8, 2010. Accessed September 9, 2012. www.lcls. org/wp-content/uploads/2009/05/CATALOGING-KITS1.pdf. 
This walkthrough is comprised of bulleted instructions and examples for creating all the fixed and variable MARC fields typically found in a catalog record for kits. The information is straightforward and useful for cataloging kits quickly. Although lacking pictorial illustrations and currency in genre and form terms, this tutorial is, in other respects, an easy-to-use guide for beginners and a quick reference for experienced catalogers.

Nimsakont, Emily D. "How to Catalog a Kit." Slideshow presentation. Last modified June 23, 2010. Accessed September 9,2012 . www.slideshare.net/nebraskaccess/ncompass -live-how-to-catalog-a-kit-4589170.

Nimsakont's presentation is an ideal resource for beginners to cataloging kits. Nimsakont goes through the entire cataloging process, from identifying kits to applying the necessary MARC fields and coding to describe them. The slides are simple and instructive with helpful photos of actual kits and screenshots of bibliographic records. Unlike the typical Slideshare presentation consisting only of slides, this one includes a recorded video of the actual presentation as an inset to the slides. The presenter's recorded use of a highlighter tool visually pinpoints key instructions and bibliographic elements on the screen.

\section{Maps}

Bertuca, David J. "Map Catalogers' Toolbox." University at Buffalo Libraries. Last modified August 25, 2011. Accessed September 9, 2012. http://library.buffalo.edu/maps/mapresources/map_cat_tools.php.

This is an exhaustive collection of map cataloging information and related resources organized in an accessible manner. Categories include physical description, classification, dates, map projections, map scale, subject headings, sample maps of different types, and gazetteers. The Map Format Field Guide outlines all essential MARC fields. A sample MARC record is provided. Further information includes links to map vendors, map cataloging associations, and a bibliography of print and online map cataloging resources. This is a top-notch resource that is routinely updated.

\section{Music Scores and Sound Recordings}

Koth, Mickey. "Music Cataloging at Yale." Yale University Library. Last modified September 4, 2012. Accessed September 9, 2012. www.library.yale.edu/cataloging/music/ musicat.htm.

This expansive resource examines most aspects of music cataloging from uniform titles and subject headings to MARC tags and call numbers. Information is organized under sections for call numbers, authority control, uniform titles, AACR2, MARC tagging, subject cataloging, sound recordings, videorecordings, language tools, and even $R D A$. Individual guides are provided for most important MARC field and cataloging decisions for sound recordings and scores. Additionally, each section features links to other general tools and supplemental online resources such as OLAC workshop presentations and Jay Weitz's column for the Music OCLC Users Group (MOUG) newsletter. Although "Music Cataloging at Yale" is intended for use by catalogers at Yale University, the information is widely applicable. Owing to its plenitude of detailed and unique guides for every facet of music cataloging along with links to other vital resources, this website is a one-stop place for music cataloging.

\section{Realia}

Lewis and Clark Library System. "Three Dimensional Artefacts [sic] and Realia." Last modified April 8, 2010. Accessed September 9, 2012. www.lcls.org/wp-content/ uploads/2009/05/THREE-DIMENSIONAL-ARTE FACTS-AND-REALIA-Including-puppets1.pdf.

Based on AACR2 chapter 10, this is an easy-to-follow guide for cataloging realia, artifacts, toys, games, models, and other three-dimensional objects. Features include AACR2 glossary definitions, instructions for creating the proper workform in OCLC Connexion, the applicable MARC fixed field codes, and examples of variable fields. Furthermore, it includes a section devoted to cataloging puppets. Although this resource lacks illustrations and examples of current genre headings, it is a handy and straightforward guide recommended for both new and experienced catalogers.

Nimsakont, Emily D. "Cataloging in 3-D: Three-Dimensional Artifacts and Realia." Slideshow presentation. Last modified March 25, 2010. Accessed September 9, 2012. www.slideshare.net/enimsakont/cataloging-in-3d-threedimensional-artifacts-and-realia.

These workshop slides provide a complete walkthrough of cataloging 3D artifacts and realia. More than 120 slides, organized by area of description, convey information clearly. The full gamut of cataloging issues is covered, including all pertinent MARC tags, subject headings, choice of main or added entry, and detailed guidance on writing 5XX notes. Also included are instructions for choosing a workform and coding the fixed fields in OCLC's Connexion. Although several other online resources offer guidelines for cataloging realia, these workshop slides are more comprehensive, better suited to novices, and oriented for practical use.

\section{Reproductions}

Furniss, Kevin, and Morag Boyd. “Describing Reproductions: 
A Series of Decisions." Slideshow presentation at OLAC Conference, Macon, Georgia, October 15, 2010. Accessed September 9, 2012. www.olacinc.org/drupal/conference/2010/ files/DescribingReproductionsOLAC2010final.pdf.

These slides explain what reproductions are and which MARC fields to use for a variety of reproduction types: microforms, facsimiles, vendor neutral e-books, and other digital formats. However, microforms and facsimiles are covered in more depth than any other formats. In addition, two methods for cataloging reproductions are discussed: describing the original or describing the reproduction. Several slides are devoted to explaining the purpose and usage of MARC fields like the 533 (Reproduction Note), 534 (Original Version Note), and 775/776 (Other Physical Form Entry/Issued With Entry). What will be most helpful to catalogers are the numerous slides containing screenshots of full MARC records for each reproduction type. The tail end of the presentation looks at the implications of $R D A$ and FRBR on cataloging reproductions, including a side-by-side example of MARC field changes between AACR2 and RDA. Cataloging reproductions is fraught with challenges and these slides clarify much on the matter.

\section{Serials}

Lewis and Clark Library System. "Cataloging Serials." Last modified September 24, 2010. Accessed September 9, 2012. www.lcls.org/wp-content/uploads/2009/05/Cataloging -serials-2010.pdf.

This is one of the few resources for cataloging serials that is utilitarian and accessible to those who are unfamiliar with the format. It includes definitions for different types of serials and how to treat them bibliographically. Clarification is provided for cataloging problematic formats and choosing whether they should be cataloged as monographs or serials. Following these general guidelines is a complete walkthrough for each pertinent MARC field and area of description for serials. Lastly, the guide discusses which fields to edit when closing a serial record (when the serial ceases publication). This compact primer provides a quick and easy approach to cataloging serials.

Program for Cooperative Cataloging. CONSER-Cooperative Online Serials Program of the PCC. Accessed September 9, 2012. www.loc.gov/aba/pcc/conser/index.html.

CONSER, the Cooperative Online Serials Program of the PCC, is the authoritative source for serials cataloging. Although the CONSER Editing Guide and CONSER Cataloging Manual must be purchased, the CONSER website features numerous free resources related to serials cataloging. ${ }^{20}$ It includes links to webinars, institutions and organizations associated with serials, instructions for joining the program, and other online resources for serials catalogers.
Information also is provided on the Serials Cataloging Cooperative Training Program (SCCTP) that offers training in serials cataloging and links to free training materials. This website provides essential information to any cataloger working with serials.

Program for Cooperative Cataloging. Integrating Resources: A Cataloging Manual: Appendix A to the BIBCO Participants' Manual and Model 35 of the CONSER Cataloging Manual, 2011 revision. Washington, DC: Program for Cooperative Cataloging, 2011. Accessed September 9, 2012. www.loc.gov/aba/pcc/bibco/documents/irman.pdf.

The 2011 revision was developed to update cataloging information on integrating resources and bring the information in line with the SCCTP workshop materials. The manual offers a thorough review of the characteristics of integrating resources and how they should be cataloged, based on AACR2 rules, Library of Congress Rule Interpretations, and MARC fields. A list of references also is provided in the manual with links to useful information. The manual provides superlative examples of how to catalog different integrating resources, including digitized texts, electronic journals, databases, websites, and resources in loose-leaf format.

\section{Special Collections, Rare Books, Manuscripts, and Archival Materials}

Barrett, Marcia. "Cataloging for Special Collections, or, Since It's All about the Collections, Collection Level Cataloging." Slideshow presentation, OLAC Conference, Macon. Georgia, October 2010. Accessed September 9, 2012. www .olacinc.org/drupal/conference/2010/files/CatalogingFor SpecialCollections.pdf.

These presentation slides serve as an overview of special collections cataloging. Information is given about the various types of special collections formats frequently encountered. Two approaches to cataloging are discussed at the outset: collection-level cataloging versus item-level cataloging. For those inclined to collection-level cataloging, the slides offer reliable examples of finding aids. Organized by AACR2's areas of description, each section is illustrated with MARC record examples. Instructions for applying fixed fields and assigning subject headings also are present. The content on each slide is lean and succinct, making it a convenient reference for hands-on cataloging. Of unique importance are the detailed instructions for creating a variety of MARC 5XX notes. At the end of the presentation is an example of a special collections photograph with a walkthrough of its cataloging process and the completed MARC record for the photograph. Considering the dearth of online resources focused on special collections cataloging, these presentation slides are exceptional and vital to special collections catalogers. 
Hildebrand, Ryan, ed. "RBMS Controlled Vocabularies." Rare Books and Manuscripts Section, Association of College and Research Libraries. Last modified January 11, 2010. Accessed September 9, 2012. www.rbms.info/committees/bibliographic_standards/controlled_vocabularies/index shtml.

Developed by the Bibliographic Standards Committee of the Rare Books and Manuscripts Sections (RBMS) of the Association of College and Research Libraries, these controlled vocabularies or thesauri will be of special interest to rare materials catalogers. The thesauri can be browsed for binding terms, genre headings, paper-making terminology, printing, and publishing terms. Terms include scope notes describing their usage, cross-references, and term relationships, e.g., broader and narrower terms. The thesauri can be browsed from an A-to-Z list or retrieved using a search box. For the cataloger assigning specialized metadata to rare materials, these controlled vocabularies will be helpful.

Holzenberg, Eric, and Larry Creider. "Directory of Web Resources for the Rare Materials Cataloger." New Mexico State University Library. Last modified July 13, 2012. Accessed September 9, 2012. http://lib.nmsu.edu/rarecat.

This exhaustive directory is a portal to a wide-ranging assortment of resources concerning various facets of rare materials cataloging. The site provides general guidelines by the RBMS along with links to unique websites about special topics for rare books. Many reference tools are supplied to help with foreign languages and authority control matters that are unique to special collections. Entire groups of links also are devoted to early cartographic materials and medieval manuscripts. Other categories of links include the history of the book, watermarks and paper, bindings, and printing and publishing information. Lastly, this directory includes a selected list of digital libraries and library catalogs of interest to special collections cataloging. Although this directory is essentially a list of links lacking descriptive annotations, it provides a gateway to some of the best online resources available to rare materials catalogers.

\section{Theses and Dissertations, Technical Reports, and Offprints}

OCLC. OCLC Bibliographic Formats and Standards. "3 Special Cataloging Guidelines." Accessed September 9, 2012. www.oclc.org/bibformats/en/specialcataloging/default shtm.

This segment of OCLC's Bibliographic Formats and Standards (BFAS) focuses on problematic materials and unusual cataloging considerations. The formats covered include theses and dissertations, reproductions, technical reports, original microform publications, offprints, integrating resources, and locally made videorecordings. The site also offers directions for creating "In Analytic" entries, institutionspecific notes, and parallel records in different languages. Each section contains concise bullet-pointed instructions coupled with sufficient MARC examples. Because of its unique content, this portion of BFAS is of great value.

\section{Miscellaneous Cataloging Resources}

"AACR2 Abbreviations (Roman Alphabet)." Yale University Library. Accessed September 9, 2012. www.library.yale.edu/ cataloging/abbrev.htm.

This resource is an A-to-Z list of common bibliographic terms and their equivalent abbreviations. Drawing on the Roman alphabet abbreviations list in appendix B of AACR2, this list of terms in the Roman alphabet will be of tremendous help to the cataloger of foreign language materials. Although the resource does not give translations or definitions of the terms, it is useful for figuring out what a foreign language abbreviation means, for example, "Ausg." for Ausgabe.

Association for Library Collections \& Technical Services. Task Force on an Appendix of Major and Minor Changes. Committee on Cataloging: Description and Access, Cataloging and Classification Section. Differences between Changes within: Guidelines on When to Create a New Record, revised edition. Chicago: ALCTS, 2007. Accessed September 9, 2012. www.ala.org/ala/mgrps/divs/alcts/resources/org/cat/ differences07.pdf.

This document outlines criteria for catalogers to consider in determining whether to create a new record or to use an existing one. The descriptions, instructions, and examples are informative and easy to follow. In addition to an overview of the basic criteria, the document includes specific guidelines for single-part monographs, multipart monographs, integrating resources, and serials. Important information is reiterated in checklist charts, which makes this document ideal for quick review.

Bannerjee, Kyle. “The Cataloging Calculator.” Library Technology Consultants. Accessed September 9, 2012. http:// calculate.alptown.com.

The Cataloging Calculator generates Cutter numbers, codes, and similar information on the basis of a supplied search term. For example, typing the last name of an author and selecting the "LC Cutter" option will convert the name into a proper Cutter number. In addition to LC Cutter numbers, it calculates geographic Cutter numbers, geographic area codes, country codes, language codes, AACR2 abbreviations, and MARC variable fields. Selection from a pulldown menu results in the display of the fixed fields for any of the format types and for authority records. All of the information populates instantly as terms are entered in the search box, 
much like the "results as you type" feature of Google’s search engine. The Cataloging Calculator is therefore an expedient and utilitarian source for constructing Cutter numbers, geographic codes, and other bibliographic metadata.

Internet Library for Librarians. "Abbreviations for Place of Publication in AACR2 and as Postal Codes." Accessed September 9, 2012. www.itcompany.com/inforetriever/ cat_260a.htm.

Here is a handy cheat sheet of the current United States postal abbreviations (e.g., TX) and their AACR2 equivalents (e.g., Tex.). The traditional abbreviation for states is AACR2's preference unless the current postal abbreviation appears on the item. Like the Cutter table, this is an essential reference for both beginning and experienced catalogers to bookmark.

Lewis and Clark Library System. "Contents Notes for 505." Last modified April 9, 2010. Accessed September 9, 2012. www.lcls.org/wp-content/uploads/2009/05/Contents-notes.pdf.

This tutorial covers the usage of both regular and enhanced contents notes. Although written as local guidelines, the information follows OCLC practice and includes copious MARC record examples. Instructions are given for recording contents notes for nonfiction, collective biographies, sound recordings, and music scores. General policies are provided for omitting certain terms, adding MARC 500 notes, 740s (Added Entry), and other cataloging decisions related to the 505 (Formatted Contents Note) field. Those seeking a detailed explanation of contents notes should find this resource beneficial.

Lewis and Clark Library System. "Dates in Bibliographic Records." Last modified August 20, 2010. Accessed September 9, 2012. www.lcls.org/wp-content/uploads/2009/05/ DATES-IN-BIBLIOGRAPHIC-RECORDS-revised.pdf.

Multiple publication, reprint, and copyright dates on a single item may pose a challenge to the cataloger when determining which date or dates to include in the bibliographic record. This resource conveniently assembles instructions for inputting dates in variable and fixed fields of bibliographic records. It presents an extensive list of MARC examples for a variety of situations involving the recording of dates, such as for copyright renewals, printing dates, reprint and reissue dates, and production dates. Considerations are made for specific formats like sound recordings, audiobooks, playaways, videorecordings, electronic resources, and realia. In cases when recording the date is challenging, this resource is an invaluable aid.

Library of Congress. "ALA-LC Romanization Tables." Accessed September 9, 2012. www.loc.gov/catdir/cpso/ roman.html.

Here is LC's archive of Romanization tables for sixty-one languages. The tables provide guidance for proper transliteration into Latin script, including full alphabetical listings of characters and their Romanization equivalent. Many tables include additional information on vowels, diacritics, lower and upper case transliterations, and other special grammatical considerations. Most of the tables have been updated in 2011 and 2012. This resource will be useful for any cataloger dealing with materials in foreign languages that utilize nonLatin script.

Library of Congress. "Library of Congress Online Catalog." Accessed September 9, 2012. http://catalog.loc.gov.

The LC online catalog provides users with a variety of ways to search LC for bibliographic records. Two options for searching are available. The first is a basic search and by subject, keyword, title or author/creator, call number, and LCCN, ISSN, or ISBN. The Guided Search option allows users to use keyword searches, Boolean operators, and searching by a particular index. Search tips are provided for both a basic search and a guided search, with results ranked by relevance. Results can be reviewed differently by using display tabs for brief record, subjects/content, full record, and MARC tags. Bibliographic records retrieved can be saved, printed, and emailed. A five-minute session timeout display can be seen in the lower-left-hand corner of the screen, letting the user know how much time remains before a bibliographic search is ended.

Library of Congress. Network Development and MARC Standards Office. "Appendix F-Initial Definite and Indefinite Articles." www.loc.gov/marc/bibliographic/bdapp-e.html.

This section of LC's MARC Standards lists common initial definite and indefinite articles in a variety of languages. Although no translations are provided, the list helps catalogers identify which words are articles. Each article is labeled with the language that utilizes it; for example, "den" is used in Danish, German, Norwegian, and Swedish. Catalogers of foreign language materials will be drawn to this resource as its practical value is evident: the list helps the cataloger know if the first word in a title is an initial definite or indefinite article, which aids in applying correct filing indicators.

OLAC Cataloging Policy Committee. "Summary/Abstracts Task Force. Summary Notes for Catalog Records." Last modified August 2002. Accessed September 9, 2012. www. olacinc.org/drupal/?q=node/21.

Not much guidance can be found on writing summary notes for electronic resources, websites, realia, sound recordings, moving image, and archival materials. This resource, however, is one of the few to offer reliable examples of summary notes, as well as bulleted instructions for writing notes for items in a variety of formats. Examples of 
complete MARC 520 (Summary, etc.) fields are supplied with clear headings designating the applicable format. In addition, a large appendix of summary note examples and a bibliography are provided for further reference. Since the fundamentals of writing summary notes have not changed much over time, the guide remains current despite its age.

Sha, Vianne T. "Ending Punctuation for Bibliographic Data." Last modified December 13, 2000. Accessed September 9, 2012. www.itcompany.com/inforetriever/punctuation.htm.

Organized in numerical MARC field order, this webpage presents examples of proper punctuation and order of subfields for each variable MARC field. Bulleted scope notes clarify which punctuation is significant for a particular field. Although similar information can be found on OCLC's Bibliographic Formats and Standards or LC's MARC Standards, this is a convenient one-page list for quick reference. Contrary to the statement at the top of the page that the list is no longer maintained as of 2000 , it was revised in 2009 to incorporate genre headings.

Sutch, Susan. "Seven Cataloging Steps Cheat Sheet." Last modified 2006. Accessed September 9, 2012. http://infopeople .org/sites/all/files/past/2006/beyond/Hand_2/steps_cheat .pdf.

The steps outlined in this guide are a handy checklist for entering the main entry, notes, subject headings, as well as variable fields for an assortment of formats. What makes this seemingly rudimentary resource special, especially for beginners, is the table on the first page listing the chief source of information for all formats. This table is invaluable to both novices and veterans who may be unfamiliar with cataloging a particular format; it is a convenient alternative to consulting AACR2 for a clear answer about the chief source of information.

\section{RDA}

American Library Association, Canadian Library Association, and CILIP: Chartered Institute of Library and Information Professionals. RDA Toolkit homepage. Accessed September 20, 2012. www.rdatoolkit.org.

Although the RDA Toolkit is a subscription service, the website itself offers access to presentations, documentation, and links to free $R D A$ resources via the "Teaching \& Training" page. One notable resource from this website is the Library of Congress Policy Statements (LCPS) found on the "Resources" tab of the "Access RDA Toolkit" webpage. LCPS is essentially the successor to the Library of Congress Rule Interpretations, and is made available at no charge.

Bothmann, Bobby. "Cataloging Electronic Resources Using
RDA: RDA 201." ALA Connect. Accessed September 19, 2012. http://connect.ala.org/files/Cataloging\%20Electronic\%20Resources\%20with\%20RDA.pdf.

Created by an authoritative expert on the subject, this presentation centers on common issues related to cataloging electronic resources using $R D A$. It walks through the areas of description affected by $R D A$, identifies the core elements used for electronic resources, and includes numerous MARC examples. Supplementary slides with full MARC record examples and screenshots of preferred sources of information can be found here: http://connect.ala.org/ files/Cataloging\%20Electronic\%20Resources\%20with\%20 RDA\%20Examples.pdf.

Griggs, Karen, and Pam Grace. "AACR2 to RDA for Audiovisual Catalogers." Utah Library Association. Accessed September 19, 2012. http://ula.org/sites/ula.org/ files/2011conference/pam\%20powerpoint4-additions.pptm.

This presentation offers a simple and focused look at cataloging audiovisual materials with RDA. Introductory content outlines the major changes occurring under $R D A$, while the bulk of the presentation supplies detailed MARC examples for DVDs, streaming videos, sound recordings, and playaways. These examples employ color-coded font to indicate the RDA elements.

Joint Steering Committee for Development of RDA. "RDA: Resource Description and Access Presentations on RDA." Accessed September 19, 2012. www.rda-jsc.org/rdapresentations.html.

This page from the Joint Steering Committee (JSC) for the Development of RDA website is a compilation of presentations made by JSC members and others involved in $R D A$ development since 2007. The list serves as an index of presentations with name of presenter(s), location, and conference name, along with links to the presentation materials. Topics covered in the presentations include basic introductions to RDA, FRBR theory, changes from AACR2 to $R D A$, and even $R D A$ 's impact on various formats. Most of the presentations are issued by authoritative figures in the $R D A$ and cataloging community.

The Library of Congress. Resource Description and Access (RDA) Information and Resources in Preparation for RDA. The Library of Congress Cataloging and Acquisitions. Accessed September 19, 2012. www.loc.gov/aba/rda.

Library of Congress' RDA website is naturally a vital resource for keeping up to date with $R D A$. It includes official documentation and news, webcasts, training modules, and $R D A$ examples. The website also is a gateway to the Catalogers Learning Workshop page, which offers a wealth of training materials concerning bibliographic and authority record creation under $R D A$. 
Maxwell, Robert L. "RDA: Resource Description and Access in Depth: Differences between AACR2 and RDA." Joint Steering Committee for Development of RDA. Accessed September 20, 2012. www.rda-jsc.org/docs/RDA_ part_2_201005.pdf.

Maxwell's presentation slides explore the differences between AACR2 and RDA through simple MARC examples and explanations of $R D A$ rules. The scope of this resource is detailed and extensive. All areas of description are thoroughly covered, in addition to definitions of RDA terminology, concepts (creators, entities, relationships, etc.), new MARC tags, and practices concerning access points.

North Carolina State University Libraries. RDA. NCSU Libraries Intranet. Accessed September 19, 2012. https:// staff.lib.ncsu.edu/confluence/display/MNC/RDA.

North Carolina State University (NCSU) was one of the $R D A$ test libraries and is providing its documentation, training materials, presentations, and other resources to the cataloging public. Among the materials made available are NCSU's test records and workforms representing a wide array of formats.

Paradis, Daniel. "Significant Changes for Cataloging Music: AACR2 vs. RDA.” Joint Steering Committee for Development of RDA. Accessed September 20, 2012. www.rda-jsc .org/docs/10_3_24_MLAannmtg_Significantchangesforcata loguingmusicAACR2vsRDA.pdf.

The presentation reviews the impact of $R D A$ on cataloging scores and sound recordings. It consists of four sections summarizing $R D A$ changes to glossary terms (e.g., score definitions), description, choice of access points, and uniform titles. Descriptive cataloging topics include replacement of the general material designation (GMD), differences in recording date, publisher numbers, and the physical description of scores and sound recordings. The presentation also clarifies choice of access points for adaptations, libretti, and cadenzas, along with an extensive look at uniform titles under RDA.

Schiff, Adam. "Welcome to the Home Page for Adam Schiff." Accessed September 19, 2012. http://faculty.wash ington.edu/aschiff.

Schiff is a recognized authority on interpreting $R D A$ and filtering information for every-day catalogers. Schiff's website lists several versions of slides from his important two-part presentation, "Changes from AACR2 to RDA," which compares descriptive cataloging and MARC coding differences between AACR2 and RDA. Addressing all areas of description, these presentation slides offer straightforward rule-byrule comparisons with $R D A$ changes designated in red font. The way this $R D A$ information is presented makes it ideal for the visually oriented learner or the cataloger wanting quick answers about descriptive cataloging under $R D A$.
Tillett, Barbara. What Is FRBR? Washington, DC: Library of Congress Cataloging Distribution Service, 2004. Accessed September 19, 2012. www.loc.gov/cds/downloads/FRBR .PDF.

Barbara Tillett's brochure is an introduction to Functional Requirements for Bibliographic Records (FRBR). Tillett is a well-known figurehead of the International Federation of Libraries and Institutions (IFLA) and an expert on FRBR and RDA. This brochure defines FRBR concepts and terminology, provides illustrations of its theoretical models, and explains what impact it can have on cataloging rules, bibliographic structures, and systems design and applications.

University of Chicago Library. "Resource Description and Access (RDA) Testing at the University of Chicago Library." University of Chicago Library Staff Web. Accessed September 19, 2012. www.lib.uchicago.edu/staffweb/depts/cat/rda .html.

This website contains $R D A$ resources used by the University of Chicago, one of the RDA test institutions. Among their unique documentation are local policies and decisions, procedures for changing AACR2 records to RDA records, MARC record examples, and University of Chicago presentations on $R D A$.

\section{Conclusion}

Although this webliography is intended to reflect current and continuously updated resources, nothing guarantees that they will remain so forever. Because of the fluctuating nature of online content, some of these resources are bound to change or even disappear in the future. Broken links are the result and this webliography is not immune from them. Despite this reality, the authors believe they have chosen stable resources that, from all indications, will continue to be hosted and updated in coming years. These free online cataloging tools should continue to serve as practical guides for catalogers.

\section{References and Notes}

1. Anglo-American Cataloguing Rules, 2nd ed. (Chicago: ALA; Ottawa: Canadian Library Association; London: CILIP: Chartered Institute of Library and Information Professionals, 2002); RDA: Resource Description \& Access (Chicago: ALA; Ottawa: Canadian Library Association; London: CILIP: Chartered Institute of Library and Information Professionals, 2011).

2. Robert E. Wolverton Jr., "Becoming an Authority on Authority Control: An Annotated Bibliography of Resources," Library Resources \& Technical Services 50, no. 1 (2006): 31-41; Beth 
M. Russell and Jodi Lynn Spillane, "Using the Web for Name Authority Work," Library Resources \& Technical Services 45, no. 2 (2001): 73-79.

3. John Blosser, Tim Hagan, and Yvonne W. Zhang, "Web Resources for Cataloging Electronic Serials and Continuing Resources: An Annotated Bibliography," The Serials Librarian 41, no. 3/4 (2002): 111-26, doi:10.1300/J123v41n03_10.

4. Nancy A. Kandoian, "Cartobibliography for Catalogers: Reference Materials to Support the Identification of Early Printed Maps," Journal of Map \& Geography Libraries 3, no. 2 (2007): 45-78, doi:10.1300/J230v03n02_04; Karen Plummer, "Web Resources for Map Cataloging: A Select Webliography," Technical Services Quarterly 23, no. 4 (2006): 89-91, doi:10.1300/J124v23n04_06.

5. M. O. Conway, "Research in Cataloging and Classification: Methods and Issues-A Selective, Annotated Bibliography," Cataloging \& Classification Quarterly 19, no. 1 (1994): 11929, doi:10.1300/J104v19n01_09.

6. Robert E. Wolverton Jr. et al., "Electronic Theses and Dissertations: Developing Standards and Changing Practices for Libraries and Universities," Technical Services Quarterly 25, supplement 1 (2008): 95-135, doi: 10.1080/J124v25nS1_a; Lona Hoover, "Cataloging Theses and Dissertations: An Annotated Bibliography," Technical Services Quarterly 19, no. 3 (2001): 21-39, doi:10.1300/J124v19n03_02.

7. Magda El-Sherbini, "Selected Cataloging Tools on the Internet," Journal of Internet Cataloging 6, no. 2 (2003): 35-90, doi:10.1300/J141v06n02_06; Laura N. Kirkland, "Resources for Catalogers: An Annotated Bibliography," Cataloging \& Classification Quarterly 40, no. 1 (2005): 79-99, doi:10.1300/ J104v40n01_06; Lyn Condron, "Web Cataloging Tools," Cataloging \& Classification Quarterly 43, no. 1 (2006): 3-6, doi:10.1300/J104v43n01_02.

8. Sarah Yoder Leroy and Suzanne Leffard Thomas, "Impact of Web Access on Cataloging," Cataloging \& Classification Quarterly 38, no. 2 (2004): 7-16, doi:10.1300/J104v38n02_03.

9. Jane M. Davis, “A Survey of Cataloging Education: Are Library Schools Listening?” Cataloging \& Classification Quarterly 46, no. 2 (2008): 182-200, doi:10.1080/01639370802177604.

10. Kirkland, "Resources for Catalogers."

11. American Library Association, "The 2012 State of America's
Libraries," special issue, American Libraries (2012): 3, accessed Sept. 9, 2012, www.ala.org/news/sites/ala.org.news/files/ content/StateofAmericasLibrariesReport2012Finalwith cover.pdf.

12. Classification Web (Washington, DC: Library of Congress, Cataloging Distribution Service, 2002- ); Cataloger's Desktop (Washington, DC: Library of Congress, Cataloging Distribution Service, 2004- ).

13. El-Sherbini, "Selected Cataloging Tools on the Internet"; Kirkland, "Resources for Catalogers"; Condron, "Web Cataloging Tools."

14. El-Sherbini, "Selected Cataloging Tools on the Internet."

15. Condron, "Web Cataloging Tools."

16. Library of Congress, "Final U.S. RDA Implementation Update from the U.S. RDA Test Coordinating Committee (January 4, 2013)," accessed Feb. 14, 2013, www.loc.gov/aba/ rda/pdf/RDA_updates_04jan13.pdf.

17. Robert M. Hiatt, Library of Congress Rule Interpretations, 2nd ed. (Washington, DC: Cataloging Distribution Services, Library of Congress (1989) with all updates through update 1 (June 2004); Subject Cataloging Manual: Classification, 1st ed. (Washington, DC: Cataloging Distribution Services, Library of Congress, 1992) with all updates through update 1 (March 1995); Subject Cataloging Manual: Shelflisting, 2nd ed. (Washington, DC: Cataloging Distribution Service, Library of Congress, 1995) and changes made through May 11, 2007; Amy M. McColl, comp., NACO Participants' Manual (Washington, DC: Cataloging Distribution Service, Library of Congress, 1994).

18. Standing Committee of the IFLA Section on Cataloguing, Functional Requirements for Bibliographic Records: Final Report (Munich: G.K. Saur, 1998).

19. Library of Congress Cataloging Policy and Support Office, Classification and Shelflisting Manual (Washington, DC: Library of Congress Cataloging Distribution Service, 2008).

20. CONSER Editing Guide (Washington, DC: Library of Congress, Cataloging Distribution Services, 1994- ); Jean L. Hirons, CONSER Cataloging Manual (Washington, DC: Library of Congress, Cataloging Distribution Services, 2002-). 